\title{
AVALIAÇÃo DA ATIVIDADE ESTROGÊNICA EM EFLUENTE DA PECUÁRIA LEITEIRA: FASE SÓLIDA E LÍQUIDA
}

\author{
EVALUATION OF ESTROGENIC ACTIVITY IN DAIRY CATTLE EFFLUENT: \\ SOLID AND LIQUID PHASES
}

Mariana Vianna Filgueiras ${ }^{a}$, Nathacha Oliveira Pires ${ }^{a}$, João Monteiro Netoa, Lorena Gotelip Costalonga ${ }^{a}$, Juliana Palermo E. dos Santosa, Marina Alonso Leitea, Lucas Martins Corrêa ${ }^{a}$, Marcelo Henrique Oteniob, Sue Ellen Costa Bottrela ${ }^{a}$ Renata de Oliveira Pereira ${ }^{a}$

a Universidade Federal de Juiz de Fora, ${ }^{b}$ Empresa Brasileira de Pesquisa Agropecuária (EMBRAPA)

\begin{abstract}
mariana.vianna@engenharia.ufj.br,oliveira.pires@engenharia.ufj.br, joao.monteiro@engenharia.ufjf.br, lorena.gotelip@engenharia.ufj..br, juliana.palermo@engenharia.ufj..br, marina.alonso@engenharia.ufjf.br, lucas.mart.correa@gmail.com, marcelo.otenio@embrapa.br, sue.bottrel@ufjf.edu.br, renata.pereira@ufjf.edu.br
\end{abstract}

Submissão: 10 de novembro de 2021

Aceitação: 13 de dezembro de 2021

\section{Resumo}

O efluente de dejetos em sistemas de confinamento animal pode ser responsável por um impacto ambiental, uma vez que, além desse efluente conter alta carga orgânica e nutrientes, ele pode apresentar micropoluentes como os Desreguladores Endócrinos. Essas substâncias são capazes de interagir com o sistema endócrino de seres humanos e animais, causando danos de diferentes magnitudes. Assim, este trabalho busca caracterizar as fases sólida e líquida do efluente da pecuária leiteira quanto à presença desses compostos e sua remoção no sistema de tratamento. O efluente analisado provém da fazenda experimental Embrapa Gado de Leite, localizada em Coronel Pacheco - MG, o qual foi submetido à um tratamento com biodigestor, seguido de uma lagoa de acumulação, sendo este recirculado para a limpeza da instalação. Foram realizadas 10 amostragens no período de setembro de 2017 a maio de 2018 da fração liquida e sólida do efluente bruto e tratado. Para a quantificação da atividade estrogênica, foi utilizado o ensaio Yeast Estrogen Screen (YES). Verificou-se concentrações elevadas de estrogenicidade nos efluentes bruto e tratado, tanto da fase líquida quanto da fase sólida. Portanto, deve-se ter cautela no manejo desses efluentes necessitando de mais estudos para avaliar o potencial de contaminação do ambiente.

Palavras-chave: Estrogenicidade, Poluição, Remoção, Tratamento, YES

\section{Abstract}

The effluent in animal confinement systems is responsible for a significant environmental impact. In addition to this effluent containing a high organic load and nutrients, it can present micropollutants such as Endocrine Disrupters. These substances can interact with the endocrine system of humans and animals, causing damage of different magnitudes. This work seeks to characterize the solid and liquid phases of the dairy cattle effluent regarding the presence of these compounds and their removal in the treatment system. This effluent comes from the experimental farm Embrapa Gado de Leite, located in Coronel Pacheco - MG, which is submitted to a treatment with biodigester, followed by an accumulation pond and is recirculated to clean the facility. 10 samplings were carried out from September 2017 to May 2018 of the liquid and solid fraction of the raw and treated effluent. To quantify estrogenic activity, the Yeast Estrogen Screen (YES) assay was used. It was possible to observe high concentrations of estrogenicity in the raw and treated effluents, both in the liquid and solid phases. Therefore, must be caution in the management of these effluents, requiring further studies to assess the potential for environmental contamination.

Keywords: Estrogenicity, Pollution, Removal, Treatment, YES 


\section{INTRODUÇÃO}

O consumo de leite, no Brasil, apresenta crescimento expressivo e superior à tendência da população, como apresentado por Vilela et al. (2017). Segundo o Anuário Leite (2019), a estimativa de consumo per capita para 0 ano de 2019 foi de 170 litros de leite por pessoa, valor ainda inferior ao recomendado pela Organização Mundial da Saúde (OMS) de 220 litros/pessoa/ano. Concomitantemente à essa elevada produção há 0 desafio de reduzir 0 impacto ambiental gerado pelos rebanhos, visto que nos sistemas de semiconfinamento, nos quais em épocas de seca, há o fornecimento de ração, a geração de efluente proveniente da limpeza das instalações pode alcançar $118 \mathrm{~L} / \mathrm{d}$ por cabeça de gado (KOZEN, 2000).

Dentre as características desse efluente destaca-se a grande variabilidade em sua composição, de acordo com a época do ano, o manejo dos animais, o estágio de desenvolvimento do animal e principalmente, a alimentação (MATOS, 2005). Ademais, esse efluente é composto por elevada concentração de matéria orgânica, nitrogênio e fósforo, caracterizando-o como uma das águas residuárias agroindustriais mais poluentes (RICO et al., 2011). Em contrapartida, justamente pela existência desses compostos, o efluente de dejetos de bovinos apresenta aplicação viável na fertirrigação, tendo em vista os benefícios ao solo, à cultura e possibilidade da redução do uso de fertilizantes químicos convencionais. Dessa forma, a aplicação do biofertilizante tem-se mostrado uma prática eficaz, que tem potencial de reduzir os impactos ambientais associados ao descarte in natura de dejetos no ambiente, sendo capaz de melhorar os atributos químicos, físicos e biológicos do solo (MACIEL et al., 2019).

Porém, um dos fatores que causa risco na utilização desse biofertilizante é a presença de micropoluentes, de origem natural ou antrópica, pela aplicação de medicamentos e hormônios no rebanho (SHORE et al., 1993). Dentre eles destacam-se os Desreguladores Endócrinos (DE) que, segundo a Environmental Protection Agency (EPA) (1997), são definidos como um "agente exógeno que interfere com síntese, secreção, transporte, ligação, ação ou eliminação de hormônio natural no corpo que são responsáveis pela manutenção, reprodução, desenvolvimento e/ou comportamento dos organismos".

Os Desreguladores Endócrinos podem ser substâncias sintéticas ou naturais. Como exemplo de substâncias sintéticas, tem-se: alquilfenóis, pesticidas, ftalatos, bifenilas policloradas (PCB), bisfenol $A$, substâncias farmacêuticas, dioxinas, entre outras. Como substâncias naturais, podemse citar os estrogênios naturais e fitoestrogênios (BILA e DEZOTTI, 2007). Os hormônios naturais estrona (E1), 17ß-estradiol (E2) e estriol (E3) são importantes para a manutenção da reprodução das células dos seios, da pele, do cérebro, desenvolvimento das características secundárias sexuais femininas e a reprodução, sendo constantemente produzidos e liberados por animais de sangue quente. $O$ hormônio sintético 17a-etinilestradiol (EE2) é amplamente utilizado em contraceptivos orais e tratamentos hormonais e o 4-n-nonilfenol (NP) é um subproduto da degradação dos surfactantes (COELHO et al., 2020).

Tais compostos são encontrados em baixas concentrações no meio ambiente, na ordem de $\mathrm{ng} / \mathrm{L}$ e ug/L. No Brasil, por exemplo, as medianas das concentrações encontradas em mananciais superficiais de estrona (E1), 17ß-estradiol (E2), estriol (E3) e 17- $\alpha$-etinilestradiol (EE2) foram de $36,3 \mathrm{ng} / \mathrm{L} ; 37,4 \mathrm{ng} / \mathrm{L} ; 5,01 \mathrm{ng} / \mathrm{L}$ e $59 \mathrm{ng} / \mathrm{L}$, respectivamente (RESENDE et al., 2017). Adeel et al. (2017) relata que a concentração sem efeito previsto para a vida aquática é em torno de 2 a 8,7 $\mathrm{ng} / \mathrm{L}$ de 17ß-Estradiol (estrogênio natural classificado como DE). Os mesmos autores relatam que para humanos, a ingestão diária aceitável é em torno de 0,0016 a $5 \mathrm{ng} / \mathrm{L}$ de $17 \beta$ Estradiol.

Alguns efeitos em ecossistemas já foram estudados como suspeitos de possuírem como causa o contato de espécies com DE, como: interferências no ciclo reprodutivo de animais; anomalias no sistema imunológico de mamíferos marinhos; aumento da incidência de cânceres de mama, de testículo e de próstata e endometriose em seres humanos (BILA, 2005). Em contrapartida, ainda que existam diversas técnicas para a quantificação e identificação dos $D E$ em amostras ambientais, há uma dificuldade em analisá-las em concentrações baixas, tal como ocorrem no ambiente, uma vez que são onerosas. A mais utilizada é a técnica analítica de cromatografia acoplada a espectrometria de massa. Destacam-se, ainda, técnicas biológicas como a Imunoadsorção Enzimática (ELISA) (DE QUEIROZ, 2011) e o Yeast Estrogen Screen (YES) (FISCHER, 2013), sendo que as técnicas biológicas podem ser realizadas in vivo e in vitro. 
O ensaio YES é um exemplo de método in vitro, através do qual é possível realizar a detecção e quantificação da atividade estrogênica, ou seja, o efeito potencial de compostos estrogênicos, através da interação da amostra com receptores de estrógeno (ROUTLEDGE e SUMPTER, 1996). Ressalta-se que para tal teste, sua sensibilidade chega a limites de quantificação de até $2 \mathrm{ng} / \mathrm{L}$ para o 17ß-estradiol. Ademais, o teste ELISA é um exemplo de teste in vivo também bastante sensível e tem por base a utilização de antígenos. Entretanto, possui um alto custo e elevado tempo de execução (DE QUEIROZ, 2011; FISCHER, 2013). Apesar das vantagens, os testes biológicos podem apresentar resultados superestimados, por causa de possíveis reações cruzadas. Por isso, os métodos cromatográficos têm se destacado pela eficiência e versatilidade nas análises, além da especificidade, sensibilidade e rapidez nos ensaios (DE QUEIROZ, 2011). Todavia, o ensaio YES tem a vantagem de analisar mais de um composto que causa atividade estrogênica $e$ possíveis efeitos sinérgico e/ou antagônicos (BILA, 2005; ROUTLEDGER \& SUMPTER, 1996).

Segundo Arnon et al. (2008), que analisaram a presença dos hormônios estrogênio e testosterona abaixo de uma lagoa de tratamento de águas residuais de uma fazenda de gado leiteiro, os DE foram capazes de percolar no solo, por meio de diferentes mecanismos de transporte, tornando também as águas subterrâneas passíveis de contaminação. Por conseguinte, ressalta-se o risco potencial associado à aplicação dessa água residuária no solo, devido à possibilidade de substâncias nocivas serem carreadas para corpos hídricos. Desta forma, o estudo visa quantificar a atividade estrogênica, utilizando o ensaio YES, nas fases sólida e líquida dos efluentes bruto e tratado advindos do sistema de tratamento na área da fazenda experimental denominada Genizinha da Embrapa Gado de Leite.

\section{MATERIAL E MÉTODOS}

O efluente estudado foi proveniente do sistema de produção Genizinha da fazenda experimental da Embrapa Gado de Leite localizada no município de Coronel Pacheco (MG), a qual opera com gado Girolando criado em semiconfinamento do tipo freestall.

O piso da estrutura de confinamento é lavado em regime diário, processo que gera o efluente bruto. Este é direcionado a um sistema de tratamento que inclui tanque de equalização, peneira centrífuga, desarenador, biodigestor anaeróbio modelo canadense com tempo de detenção hidráulica (TDH) de 32 dias e uma lagoa de acumulação com TDH de 7 dias (MENDONÇA, 2017). O efluente, após ser submetido ao tratamento, é armazenado na lagoa, a qual opera como um tanque de detenção, exposto à pluviosidade. Em seguida, é bombeado para que possa ser reutilizado na limpeza das instalações, ciclo que dura aproximadamente 20 dias. Com o término do ciclo a lagoa é esvaziada e preenchida com água limpa, iniciando um novo ciclo.

As campanhas de amostragem foram realizadas no período de setembro de 2017 a maio de 2018, com exceção dos meses de outubro e abril, devido a problemas na logística da coleta. Os pontos de coleta denominados 1,2 e 3 são referentes às amostras: efluente bruto, efluente da saída do biodigestor e efluente tratado, respectivamente, como indicado na Figura 1. É importante ressaltar que, somente a partir de janeiro de 2018, o ponto 2 foi inserido na amostragem.

A fim de caracterizar o efluente foram realizadas as seguintes análises físico-químicas: Demanda Bioquímica de Oxigênio (DBO), Demanda Química de Oxigênio (DQO), Nitrogênio Total Kjeldahl (NTK), Nitrogênio Orgânico (Norg), Nitrogênio Amoniacal (Namoniacal), Fósforo Total $\left(P_{\text {total }}\right)$, Sólidos Totais (ST), Sólidos Suspensos Totais (SST) e Sólidos Dissolvidos Totais (SDT). Todos os ensaios foram realizados de acordo com o Standard Methods for the Examination of Water and Wastewater (APHA, 2017), no Laboratório de Qualidade Ambiental (LAQUA) da Universidade Federal de Juiz de Fora (UFJF).

Além da caracterização do efluente, a quantidade de animais presentes durante o período de recirculação do efluente armazenado na lagoa e dados de pluviosidade foram levantados a fim de se fazer correlações capazes de esclarecer o comportamento da atividade estrogênica nos efluentes em estudo. Os dados de pluviosidade foram monitorados com base nas informações da estação meteorológica A557, localizada em Coronel Pacheco, obtidos pelo Instituto Nacional de Meteorologia (INMET) (2018). Essas variáveis estão apresentadas na Tabela 1.

A quantificação da atividade estrogênica envolveu as etapas sequenciais de separação das fases sólida e líquida da amostra, Extração em Fase Sólida (SPE) e detecção da atividade estrogênica através do ensaio YES. 
Para a separação das fases líquida e sólida do efluente foi utilizado o procedimento adaptado de Silva (2015), no qual, diferentemente do presente estudo, foram analisados água de rio e sedimentos. Além disso, o valor do $\mathrm{pH}$ foi ajustado para 2 na preparação das amostras do rio, e no procedimento com o efluente da pecuária leiteira foi utilizado o pH igual a 3 . Essa metodologia, viabilizou a análise da concentração estrogênica nas duas matrizes e suas distintas interações com o sistema de tratamento em estudo, bem como suas variáveis, conforme descrito na Figura 2. Após o procedimento de separação entre as fases, foram submetidos $150 \mathrm{~mL}$ da amostra da fase líquida e $10 \mathrm{~g}$ da amostra da fase sólida seca e posteriormente dissolvida para a etapa de extração, conforme apresentado na Figura 2.

Figura 1 - Sistema de tratamento e recirculação do efluente oriundo de dejetos bovinos da Fazenda Genizinha Embrapa Gado de Leite (Coronel Pacheco-MG)

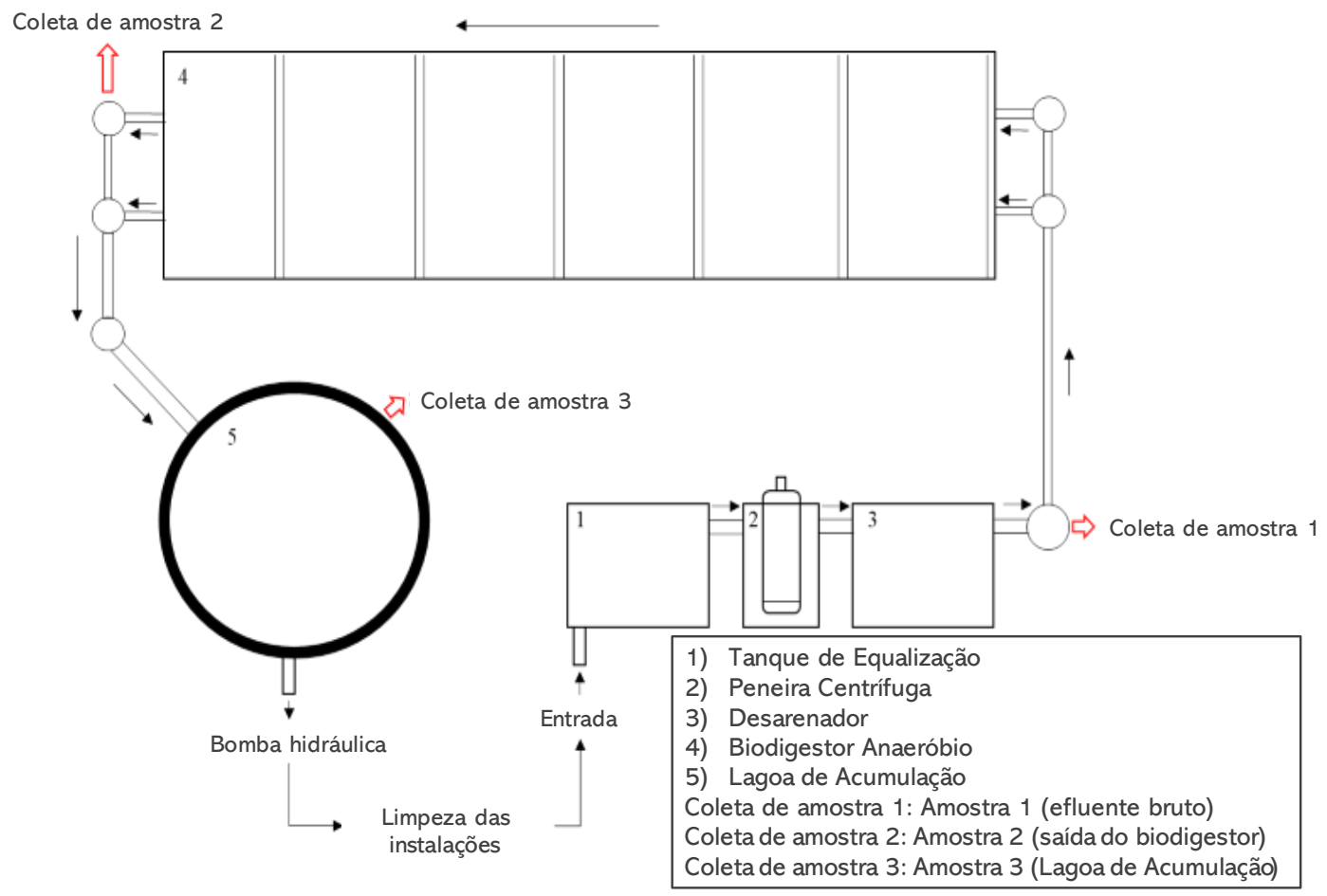

Fonte: autoria própria.

Tabela 1 - Data da coleta do efluente, duração do ciclo de recirculação do sistema, número de animais e pluviosidade do mês

\begin{tabular}{c|c|c|c|c}
$\begin{array}{c}\text { Meses e anos das } \\
\text { Coletas }\end{array}$ & Data & $\begin{array}{c}\text { Duração do Ciclo da } \\
\text { Recirculação da lagoa (d) }\end{array}$ & $\begin{array}{c}\text { Número de } \\
\text { Animais }\end{array}$ & Pluviosidade (mm) \\
\hline Set/17 & $13 / 09$ & 15 & 115 & 1,4 \\
Nov/17 & $20 / 11$ & 29 & 150 & 161,0 \\
Dez/17 & $11 / 12$ & 20 & 107 & 154,4 \\
Jan/18 & $22 / 01$ & 13 & 71 & 250,6 \\
Fev/18 & $19 / 02$ & 18 & 72 & 128,0 \\
Mar/18 & $19 / 03$ & 11 & 86 & 159,2 \\
Mai/18 & $23 / 05$ & 40 & 78 & 42,0
\end{tabular}

Fonte: autoria própria. 
Figura 2 - Esquema representativo de manipulação das amostras para quantificação da atividade estrogênica na fase sólida e líquida das amostras de efluente oriundo de dejetos bovinos da Fazenda

Genizinha Embrapa Gado de Leite (Coronel Pacheco-MG)

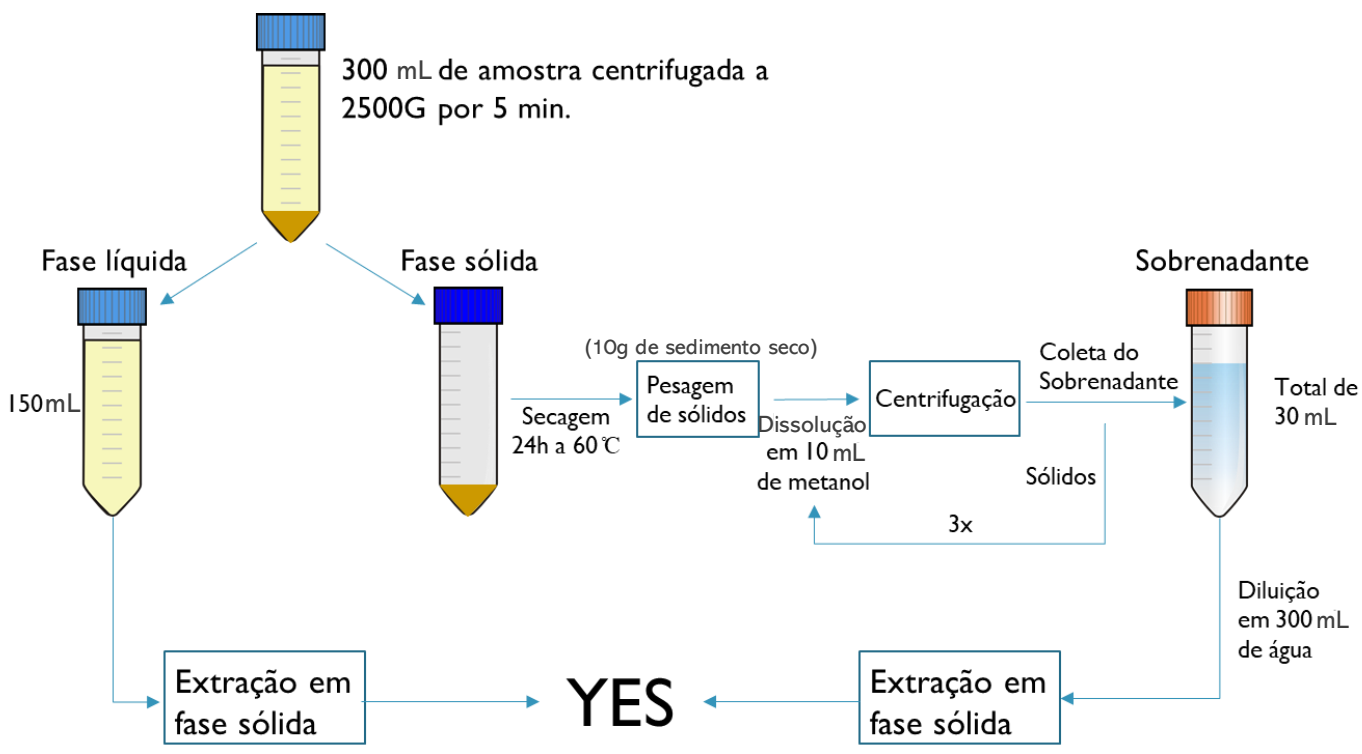

Fonte: autoria própria.

Realizou-se a Extração em Fase Sólida de acordo com o método de Bila (2005), na qual foram utilizados manifold (Agilent Vac Elut $\circledast$ ) e cartuchos de extração C18 (Agilent Technologies, 500 mg, 6 $\mathrm{mL}$ ), condicionados com $6 \mathrm{~mL}$ de hexano, $2 \mathrm{~mL}$ de acetona, $6 \mathrm{~mL}$ de metanol e, por fim, $10 \mathrm{~mL}$ de água deionizada com $\mathrm{pH}$ ajustado para 3. Após a extração das amostras, sendo os volumes variados de acordo com a fase em análise, tal como descrito na Figura 2, ocorreu a eluição com $4 \mathrm{~mL}$ de acetona, seguido da secagem em fluxo de nitrogênio e ressuspensão em $1 \mathrm{~mL}$ de etanol absoluto. O E2 ( $\geq 98 \%)$ foi obtido da SigmaAldrich ${ }^{\circledR}$ e os solventes acetona (P.A), hexano (P.A), ácido clorídrico (P.A., 37\%), metanol (P.A), ácido nítrico (P.A., 65\%) e o etanol absoluto (P.A., $>99,9 \%$ ) foram obtidos da Synth $\AA^{\circ}$. Os reagentes utilizados no ensaio YES, com grau elevado de pureza, também foram obtidos da Sigma-Aldrich $\AA$ ou da Synth $\AA$. A cultura de leveduras utilizada no ensaio foi obtida de uma coleção de culturas desses microrganismos, em parceria com a Universidade Federal de Viçosa. Atualmente, há a manutenção da cultura no Laboratório de Qualidade Ambiental (LAQUA) da Universidade Federal de Juiz de Fora.

Os ensaios YES foram realizados de acordo com a metodologia de Routledger e Sumpter (1996), com adaptações de Bila (2005), e têm como princípio a exposição da amostra a uma solução contendo clorofenol vermelho- $\beta$-Dgalactopiranosida (CPRG) e uma cepa específica da levedura Saccharomyces cerevisiae, a qual é capaz de metabolizar compostos estrogênicos resultando em reações químicas que causam alteração na cor do substrato, de amarelo para vermelho, possibilitando sua quantificação através de técnicas de espectrofotometria ao comparar a concentração de uma curva padrão com o resultado obtido em equivalentes de $17 \beta$-estradiol (EQ-E2) das amostras analisadas. O resultado é reportado em equivalentes de $17 \beta$-estradiol (EQE2) e a curva possui escala logarítmica com concentrações de E2 entre 2724 ng. $\mathrm{L}^{-1}$ e 1,33 $\mathrm{ng} \cdot \mathrm{L}^{-1}$.

O procedimento do ensaio YES é iniciado com a distribuição de $200 \mu \mathrm{L}$ de solução padrão de E2 no primeiro poço da primeira fileira de uma microplaca de 96 poços. Com o etanol como solvente, é realizada uma diluição 1:1 em todos os 12 poços da fileira, resultando em uma série de diluições no intervalo de concentrações de 2724 ng. $\mathrm{L}^{-1}$ a 1,33 $\mathrm{ng} \cdot \mathrm{L}^{-1}$. Esse processo é repetido também na terceira fileira da placa, para se obter uma duplicata da curva padrão de E2. Nas fileiras 5 e 7 são colocadas as amostras que serão analisados (em duplicata) seguido o procedimento similar descrito para o padrão de E2. As fileiras contendo as amostras e o padrão de E2 são intercaladas com fileiras preenchidas apenas com 
etanol, a fim de evitar qualquer possível contaminação cruzada. Essa é denominada microplaca de diluição, por ter tal finalidade.

Com isso, $10 \mu \mathrm{L}$ da solução de todos os poços são transferidos para uma nova microplaca, mantendo a posição relativa de cada poço em relação a placa de diluição. Após a evaporação completa das amostras, cada poço recebe $200 \mu \mathrm{L}$ da solução contendo CPRG a uma concentração de $80{\mathrm{mg} . \mathrm{L}^{-1}}^{\mathrm{e}}$ aproximadamente $4 \times 10^{7}$ células de levedura, as quais foram garantidas através de medições de Densidade Óptica em espectrofotômetro. Depois disso, a placa é selada e agitada, e após 3 dias de incubação a $32^{\circ} \mathrm{C}$, a mudança de coloração dos poços contendo atividade estrogênica já se torna visível a olho nu. Dessa forma, a placa é aberta e as leituras de espectrofotometria são realizadas nos comprimentos de onda de $540 \mathrm{~nm}$ e $620 \mathrm{~nm}$, que representam a absorbância gerada pela cor e pela turbidez dos poços, respectivamente. A partir dos dados de leitura, a absorbância ajustada é calculada (Equação 1). O equipamento utilizado para as leituras foi a leitora de placas Multiskan FCTM (Thermo scientific ${ }^{\circledR}$ ).

$$
\text { Absorbância corrigida }=A b s_{540 \mathrm{~nm}}-\left(\text { Abs }_{620 \mathrm{~nm}}-{\text { Blank } \left.A b s_{620 \mathrm{~nm}}\right)}\right.
$$

Com isso, uma curva do tipo dose-resposta foi obtida através dos dados de concentração e absorbância das series de diluição da solução padrão. Essa curva foi obtida através da Equação 2, relacionando a absorbância ajustada (y) com a concentração de atividade estrogênica na escala logarítmica $(x)$, utilizando-se das constantes de máxima indução $\left(A_{1}\right)$, o limite de detecção da análise $\left(A_{2}\right)$, o valor de EC50 (concentração que gera a resposta equivalente à metade da máxima indução obtida, representada por $X_{0}$ na equação) e o coeficiente angular obtido pela regressão linear da região central da curva dose-resposta gerada (p).

$$
y=\frac{A_{1}-A_{2}}{1+\left(\frac{x}{x_{0}}\right)^{p}}+A_{2}
$$

Ademais, os resultados reportados foram as médias aritméticas das duplicatas realizadas, considerando as devidas diluições e concentrações realizadas ao longo da metodologia.

A metodologia de preparação da amostra e do ensaio YES foi realizada com amostras branco de controle, que consistia em água deionizada, a fim de identificar falsos positivos e possíveis contaminações durante o procedimento.

Para realização das análises estatísticas foi utilizado o software Minitab ${ }^{\circledR} 18$. Utilizou-se o teste estatístico de Mann-Whitney para verificar se houve diferença significativa entre os valores medianos da atividade estrogênica em cada ponto de coleta, a um nível de significância de 5\%. Também a esse nível de significância, realizou-se o teste da Razão $Q$ de Dixon para verificar a presença de outliers no conjunto de dados de estrogenicidade obtidos. Por fim, utilizou-se a Correlação de Pearson, para medição do grau de correlação entre possíveis variáveis que influenciaram na atividade estrogênica no sistema de tratamento.

\section{RESULTADOS E DISCUSSÃO}

$\mathrm{Na}$ Tabela 2, verificam-se os resultados obtidos nas análises físico-químicas dos efluentes, as eficiências de remoção dos parâmetros físicoquímicos do biodigestor e a eficiência global do sistema.

Segundo Bitton (2005), a redução das concentrações de DQO, DBO e ST (Tabela 2), após 0 tratamento é devido a alta biodegradabilidade da matriz, sendo recomendável um tratamento biológico como etapa inicial para efluentes altamente concentrados em matéria orgânica, como o efluente do presente estudo. Ademais, o valor da remoção de DBO encontra-se acima do exigido pela legislação de lançamento de efluentes, a resolução CONAMA no 430/2011, o qual é no mínimo 60\%.

Além disso, como esperados para processos de tratamento anaeróbios, nos quais não ocorrem a nitrificação, há baixa remoção de NTK considerando a entrada e a saída do biodigestor, conforme constatado na Tabela 2. Já em relação à eficiência global de remoção, a qual considera os valores obtidos no efluente coletado na lagoa, foi possível observar remoções tanto para o parâmetro NTK, quanto Nitrogênio Orgânico, indicando a possível ocorrência de nitrificação e amonificação na lagoa (Tabela 2). 
Tabela 2 - Caracterização físico-química dos efluentes bruto, da saída do biodigestor e da lagoa de armazenamento da Fazenda Genizinha Embrapa Gado de Leite (Coronel Pacheco-MG) e respectivas eficiências de remoção

\begin{tabular}{|c|c|c|c|c|c|}
\hline Parâmetros & Efluente Bruto* & $\begin{array}{c}\text { Saída do } \\
\text { Biodigestor* }\end{array}$ & Efluente Lagoa* & $\begin{array}{c}\text { Eficiência } \\
\text { Biodigestor ** (\%) }\end{array}$ & $\begin{array}{c}\text { Eficiência Global } \\
* *(\%)\end{array}$ \\
\hline NTK (mg/L) & 379,9 & 351,7 & 307,3 & 7,4 & 19,1 \\
\hline $\begin{array}{c}\mathrm{N} \text { amoniacal } \\
\left(\mathrm{mgNH}_{4} / \mathrm{L}\right)\end{array}$ & 267,3 & 248,8 & 274,4 & 6,9 & $-2,6$ \\
\hline $\mathrm{N}$ org $(\mathrm{mg} / \mathrm{L})$ & 177,6 & 122,5 & 63,3 & 31,0 & 64,4 \\
\hline $\begin{array}{l}\text { Fósforo total } \\
\text { (mgP/L) }\end{array}$ & 52,45 & 54,8 & 52,35 & $-4,5$ & 0,2 \\
\hline DQO (mg/L) & 5261,5 & 1967,1 & 1295,7 & 62,6 & 75,4 \\
\hline $\mathrm{DBO}\left(\mathrm{mgO}_{2} / \mathrm{L}\right)$ & 761,2 & 88,8 & 58,2 & 88,3 & 92,3 \\
\hline ST (mg/L) & 7381,7 & 4050,0 & 3738,25 & 45,1 & 49,4 \\
\hline $\mathrm{SST}(\mathrm{mg} / \mathrm{L})$ & 4714,2 & 2137,1 & 369,9 & 54,7 & 92,1 \\
\hline SDT (mg/L) & 4379,1 & 3060,5 & 3547,7 & 30,1 & 19,0 \\
\hline
\end{tabular}

* mediana, ${ }^{* *}$ mediana das eficiências de remoção de cada dia de coleta, número de amostras $=7$. Eficiência do biodigestor (remoção dos parâmetros entre o efluente da saída do biodigestor e efluente bruto. Eficiência global (remoção dos parâmetros entre o efluente da lagoa e efluente bruto). Fonte: autoria própria.

Os valores encontrados para as eficiências no biodigestor, considerando a remoção de nitrogênio e fósforo, são os esperados em processos anaeróbios (JORDÃO e PESSOA, 2010) e, assim, por conterem ainda elevadas concentrações dos referidos parâmetros, os efluentes da bovinocultura têm grande potencial de uso na fertirrigação (MACIEL et al., 2019).

Em relação aos resultados da quantificação da atividade estrogênica pelo ensaio YES, as curvas dose-resposta dos ensaios da fase líquida e sólida do efluente apresentaram EC50 (concentração que gera $50 \%$ da resposta do controle positivo do teste) de $121 \pm 6 \mathrm{ng} . \mathrm{L}^{-1}$ e limite de detecção médio de $1,06 \pm 0,9 \mathrm{ng} \cdot \mathrm{L}^{-1}$, considerando todas as amostras coletadas de ambas as fases, no período em estudo $(n=7)$. $O$ valor de EC50 alcançado nos ensaios demonstra uma sensibilidade adequada do teste (CITULSKI e FARAHBAKHSH, 2012) que apresenta baixo limite de detecção, adequado para quantificação de DE em amostras ambientais, através do ensaio YES (ROUTLEDGE e SUMPTER, 1996).

Analisou-se, portanto, a estrogenicidade em todas as etapas do sistema de tratamento. A Figura 3 representa o gráfico box-plot dos valores de atividade estrogênica da fase líquida do efluente em estudo.

O efluente líquido bruto apresentou 575,3 ngE2EQ.L-1 como a mediana dos valores de concentração encontrados. Tal valor é superior às concentrações de atividade estrogênica encontradas em esgoto bruto doméstico que, segundo Muller et al. (2008), se encontram na faixa de 150 a 185 ngE2EQ.L-1. Esse efluente, se não tratado adequadamente, pode gerar impactos às comunidades aquáticas se lançado em corpo hídrico e até na saúde humana se consumir essa água sem tratamento adequado (LATHERS 2001; GREGORASZKZUC e KOVACEVIC, 2013), ou em águas subterrâneas se disposto no solo (ARNON et al., 2008). Porém, tem-se a necessidade de mais estudos nessa área, uma vez que o presente artigo é um dos primeiros a identificar atividade estrogênica nos efluentes de bovinocultura do Brasil.

Com o teste estatístico de Mann-Whitney, foram comparados os valores de estrogenicidade em cada etapa do sistema de tratamento da fase líquida e verificou-se que não houve diferença estatisticamente significativa a um nível de $95 \%$ de significância entre as medianas, as quais foram de 575,3 ngE2EQ.L-1, 714,5 ngE2EQ.L-1 e 620,0 ngE2EQ.L-1 para o esgoto bruto, saída do biodigestor e efluente tratado, respectivamente. Ou seja, as concentrações de atividade estrogênica ao longo do tratamento não são consideradas diferentes em cada ponto coletado, mostrando uma possível ineficiência do sistema em relação à estrogenicidade. Todavia, também pode ter 
ocorrido uma degradação ou uma reação levando à formação de compostos que ainda possuem atividade estrogênica.

A mediana das atividades estrogênicas do

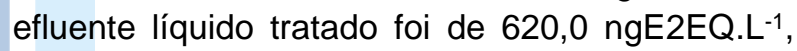
valor ainda maior do que o efluente bruto. Verificouse, portanto, o potencial poluidor desse efluente, demonstrando a necessidade de tratamentos complementares com 0 intuito de promover a remoção de compostos causadores de atividade estrogênica.

A estrogenicidade da fase sólida do efluente também foi analisada, e encontra-se representada na Figura 4.

Figura 3 - Gráfico box-plot da atividade estrogênica da fase líquida do efluente bruto ( $N=7)$, da saída do biodigestor anaeróbio ( $\mathrm{N}=4)$ e da saída da lagoa de armazenamento $(\mathrm{N}=7)$ da Fazenda Genizinha Embrapa Gado de Leite (Coronel Pacheco-MG)

$\mathrm{N}=$ número de amostras
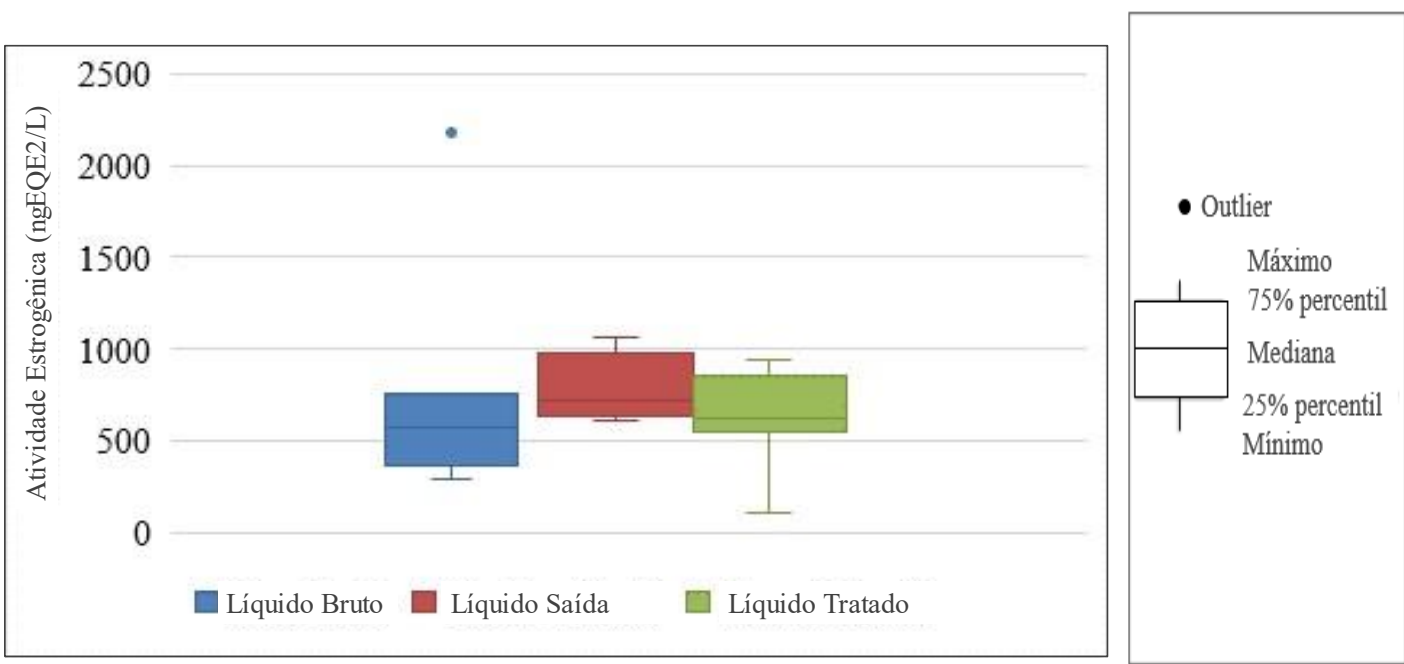

Fonte: autoria própria.

Figura 4 - Gráfico box-plot da atividade estrogênica da fase sólida do efluente bruto $(\mathrm{N}=7)$, da saída do biodigestor anaeróbio ( $\mathrm{N}=4)$ e da saída da lagoa de armazenamento $(\mathrm{N}=7)$ da Fazenda Genizinha Embrapa Gado de Leite (Coronel Pacheco-MG)

$\mathrm{N}=$ número de amostras

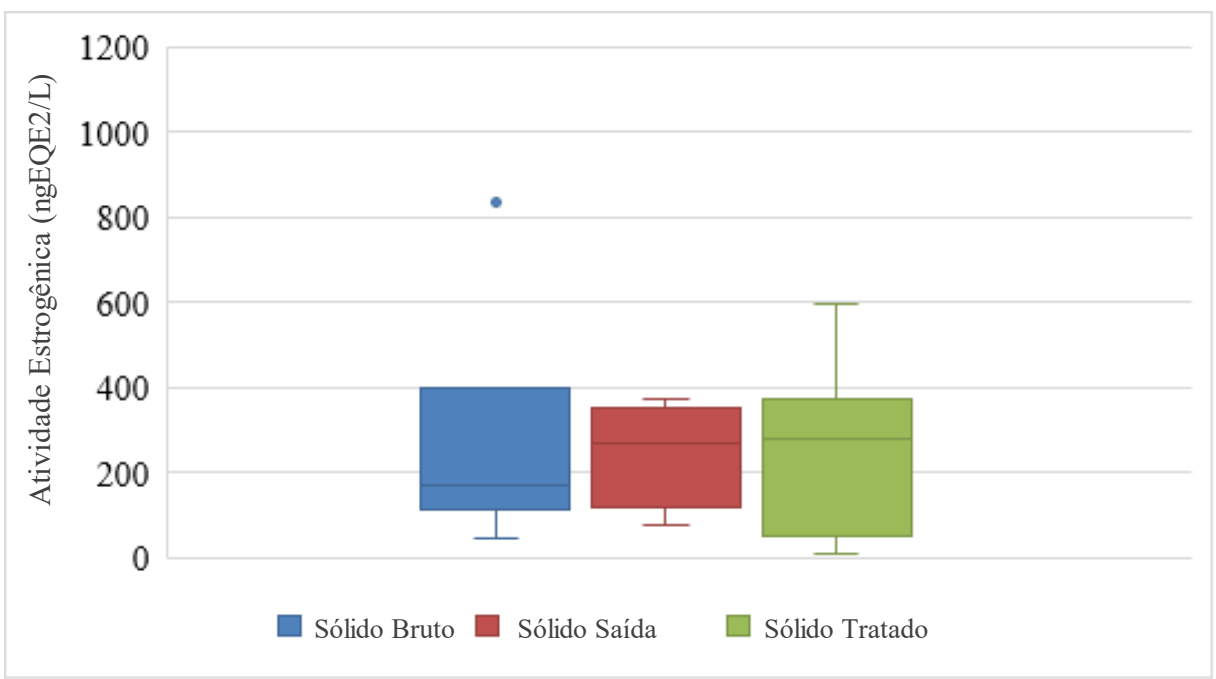

Fonte: autoria própria. 
A fase sólida bruta obteve uma mediana das concentrações de 167,8 ngE2EQ.g ${ }^{-1}$, valor elevado de estrogenicidade. Entretanto, como já discutido, não se pode afirmar que a concentração encontrada não gera impactos ambientais, uma vez que o presente estudo é um dos primeiros também a analisar a atividade estrogênica na fase sólida de um efluente de bovinocultura do Brasil. Além disso, a fração sólida apresenta um caminho de entrada mais direto nos seres vivos através da cadeia alimentar, supondo um maior risco ambiental (VEJA-MORALES, 2013).

Ademais, também com o teste estatístico de Mann-Whitney, foram comparados os valores da estrogenicidade na fase sólida, verificando que a diferença entre as medianas também não foi estatisticamente significativa a um nível de $95 \%$ de significância. Tais medianas apresentaram valores de 167,8 ngE2EQ.g-1 para o esgoto bruto, 269,3 ngE2EQ. $g^{-1}$ para o efluente da saída do biodigestor e 276,1 ngE2EQ.g ${ }^{-1}$ para o efluente tratado. Com isso, as concentrações de atividade estrogênica da fase sólida do efluente também não são consideradas diferentes em cada ponto coletado, mostrando uma possível ineficiência do sistema também para essa fase.

A mediana das concentrações da fase sólida após o tratamento foi de 276,1 ngE2EQ.g ${ }^{-1}$, indicando que essa fase também pode ser uma fonte de DE para o ambiente. Segundo Aquino et al. (2013), no processo de tratamento de esgoto pode ocorrer o transporte de DE da fase líquida para a sólida, podendo explicar os baixos valores de remoção da atividade estrogênica. Ademais, tais valores estão acima das faixas encontradas por Vega-Morales et al. (2013) no estudo com águas residuárias, as quais foram entre 8,6 e 238,8 ngE2. g $^{-1}$ para as amostras de lodo e 10,8 a 192,8 ngE2. $\mathrm{g}^{-1}$ para o material particulado.

Com os valores da atividade estrogênica em cada ponto de amostragem, pôde-se calcular a eficiência de remoção da estrogenicidade, representada pela Tabela 3 , tanto na saída do biodigestor quanto no final do tratamento, que inclui a lagoa.

Tabela 3 - Eficiências da atividade estrogênica nas etapas do tratamento do efluente oriundo de dejetos bovinos da Fazenda Genizinha Embrapa Gado de Leite (Coronel Pacheco-MG)

\begin{tabular}{c|c|c|c|c}
$\begin{array}{c}\text { Meses e anos das } \\
\text { Coletas }\end{array}$ & $\begin{array}{c}\text { Eficiência } \\
\text { Biodigestor Fase } \\
\text { Líquida (\%) }\end{array}$ & $\begin{array}{c}\text { Eficiência } \\
\text { Biodigestor Fase } \\
\text { Sólida (\%) }\end{array}$ & $\begin{array}{c}\text { Eficiência } \\
\text { Global Fase } \\
\text { Líquida (\%) }\end{array}$ & $\begin{array}{c}\text { Eficiência Global } \\
\text { Fase Sólida (\%) }\end{array}$ \\
\hline Set/17 & & & 56,6 & 55,3 \\
Nov/17 & $-267,3$ & $-97,4$ & $-0,4$ & 92,9 \\
Dez/17 & $-47,5$ & $-734,2$ & $-94,9$ & 24,1 \\
Jan/18 & $-106,7$ & $-70,0$ & 69,9 & $-366,1$ \\
Fev/18 & $-6,7$ & 77,0 & 3,8 & $-5,9$ \\
Mar/18 & $-77,1$ & $-83,7$ & $-0,4$ & 63,0 \\
Mai/18 & & & & 24,1 \\
\hline $\begin{array}{c}\text { Mediana das } \\
\text { eficiências (\%) }\end{array}$ & $-77,7$ &
\end{tabular}

Fonte: autoria própria.

Constatou-se, portanto, que apenas duas das remoções, coleta de setembro e março, foram suficientes para diminuir a atividade estrogênica do efluente, conforme a Tabela 3. Segundo Cano et al. (1997), a maioria dos estrogênios são excretados em sua forma conjugada, os quais são polares e biologicamente menos ativos e mais solúveis em água quando comparados aos não conjugados (D'ASCENZO et al., 2003). Entretanto, ao longo da estação de tratamento do efluente, algumas bactérias do meio, como a Escherichia coli, são capazes de desconjugar os estrogênios, aumentando as concentrações de atividade estrogênica ao final do tratamento biológico (FENT 
et al., 2006), o que pode ter ocorrido nesse sistema, visto o aumento da atividade estrogênica, representado na Tabela 3 por uma eficiência negativa de remoção.

Além disso, foram estudadas as correlações dos valores de atividade estrogênica com a duração do ciclo de recirculação da lagoa, com o número de animais e com a pluviosidade do mês. Contudo, a primeira variável não apresentou nenhuma relação com as concentrações de estrogenicidade.

Segundo o teste de Correlação de Pearson, a pluviosidade mostrou influência nos resultados da atividade estrogênica do efluente líquido, com um coeficiente de correlação de $r=-0,73$, o que indica uma relação linear negativa. $A$ correlação com a fase sólida do efluente apresentou o mesmo valor de coeficiente. Tal relação pode ser justificada pela diluição do efluente, uma vez que o sistema de tratamento é aberto e exposto à precipitação. $\mathrm{A}$ Figura 5 representa a correlação entre a atividade estrogênica da amostra bruta de ambas as fases e a pluviosidade do mês, exceto setembro de 2017, o qual foi considerado um outlier, de acordo com o teste de Dixon.

A contribuição de compostos que causam atividade estrogênica média por animal foi de 5,6 ngE2EQ.L-1 no efluente líquido (Figura $6 A$ ) e 2,2 ngE2EQ. $g^{-1}$ na fase sólida (Figura 6B). Todavia, como esse sistema possui recirculação, pode haver um efeito de acumulação da atividade estrogênica, levando a um valor superestimado por animal. Contudo, para esse tipo de sistema é representativo.

Figura 5 - Gráfico da correlação da atividade estrogênica com a pluviosidade do mês de coleta:

A) fase líquida bruta *B) fase sólida bruta
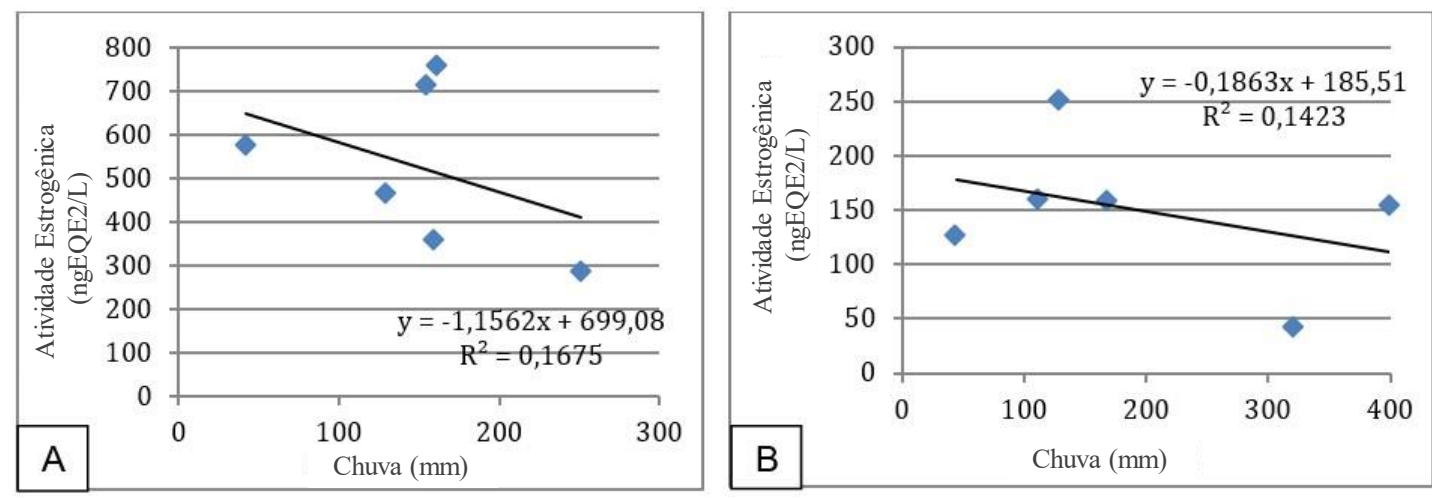

*coleta de setembro não foi considerada por ser um outlier

Fonte: autoria própria.

Figura 6 - Gráfico da contribuição por animal na concentração de atividade estrogênica: A) na fase líquida do efluente bruto *B) na fase sólida do efluente bruto
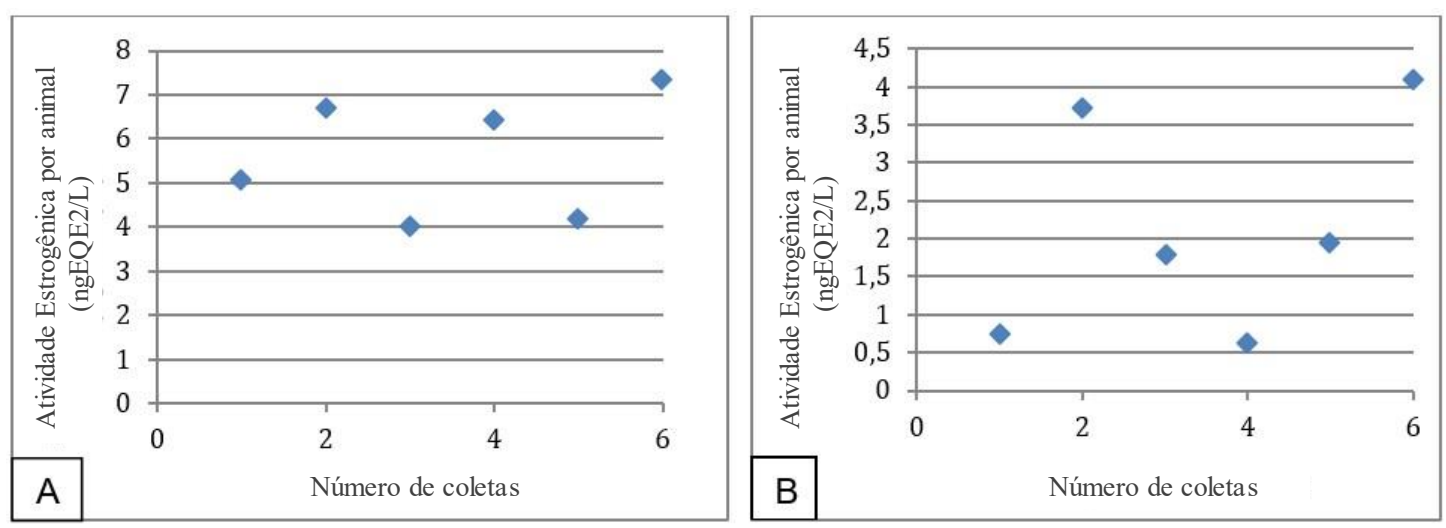

*coleta de setembro não foi considerada por ser um outlier

Fonte: autoria própria. 


\section{CONCLUSÃO}

Com os resultados obtidos, pôde-se concluir que o biodigestor utilizado no tratamento do efluente da pecuária leiteira foi ineficiente para remoção da atividade estrogênica, visto que as concentrações de atividade estrogênica no efluente tratado das fases líquida e sólida foram consideradas elevadas. Todavia, a redução da carga orgânica e aumento e/ou baixa remoção dos nutrientes, principalmente nitrogênio e fósforo, faz com que o efluente final do sistema possa ser reaproveitado como biofertilizante. Assim, ressaltase a necessidade de mais estudos nesse tipo de efluente, uma vez que o presente artigo é um dos primeiros a identificar atividade estrogênica nos efluentes de bovinocultura do Brasil.

\section{Agradecimentos}

À Pró-Reitoria de Pós-Graduação e Pesquisa (PROPP) da Universidade Federal de Juiz de Fora (UFJF) pelas bolsas de iniciação cientifica, ao LAQUA da UFJF pelo auxílio nas análises e à Embrapa Gado de Leite pelo financiamento do projeto.

\section{REFERÊNCIAS}

ADEEL, M.; SONG, X.; WANG, Y.; FRANCIS, D.; YANG, Y. Environmental impact of estrogens on human animal and plant life: A critical review. Environment International, v. 99, p. 107-119, 2017. DOI:

https://doi.org/10.1016/j.envint.2016.12.010.

APHA, AWWA, WPCF: American Public Health Association, American Water Works Association, Water Environment Federation. Standard methods for the examination of water and wastewater. $23 \mathrm{ed}$. Washington D. C. 2017.

AQUINO, S. F.; BRANDT, E. M. F.; CHERNICHARO, C. A. L. Remoção de fármacos e desreguladores endócrinos em estações de tratamento de esgoto: revisão da literatura. Eng. Sanit. Ambient., v. 18, n. 3, p. 187-204, 2013. DOI: https://doi.org/10.1590/S141341522013000300002 .

ARNON, S.; DAHAM, O.; ELHANANY, S.; COHEN, K.; PANKRATOV, I.; GROSS, A.; RONEN, Z.; BARAM, S.; SHORE, L. S. Transport of testosterone and estrogen from dairy-farm waste lagoons to groundwater. Environmental Science Technology. v. 42, n. 15, p. 5521-5526, 2008.2 DOI: https://doi.org/10.1021/es800784m.
BILA, D. M. Degradação e remoção da atividade estrogênica do desregulador endócrino 17 $\beta$ estradiol pelo processo de ozonização. 2005. Tese de doutorado, Universidade Federal do Rio de Janeiro (UFRJ), Rio de Janeiro, 2005.

BILA, D. M.; DEZOTTI, M. Desreguladores endócrinos no meio ambiente: efeitos e consequências. Química Nova, v. 30, n. 3, p. 651-666, 2007.

BITTON, G. Wastewater Microbiology. 3 ed. New York: Willey Liss Inc., 2005.

BOND, W. J. Effluent irrigation-an environmental challenge for soil Science. Australian Journal of Soil Research. v. 36, n. 4, p. 543-555, 1998.

CANO, A.; ROURA, A. C.; CORTIT, L. I. Farmacología de los anticonceptivos hormonales orales. Manual de anticoncepcíon hormonal oral. Zaragoza: Sociedad Española de Contracepción, p. 75-99, 1997.

CHEN, X.; HU, J. Degradation of $17 \beta$-estradiol and its conjugates: Effects of initial concentration and MLSS concentration. ProcessBiochemistry, v. 44, n. 12, p. 1330-1334, 2009. DOI: https://doi.org/ 10.1016/j.procbio.2009.07.007.

CITULSKI, J.; FARAHBAKHSH, K. Overcoming the toxicity effects of municipal wastewater sludge and biosolid extracts in the Yeast Estrogen Screen (YES) assay. Chemosphere, v. 87, n. 5, p. 498-503, 2012. DOI: https://doi.org/10.1016/j.chemosphere.2011.12.043.

1COELHO, L. H. G. et al. Estrogenic Hormones in São Paulo Waters (Brazil) and Their Relationship with Environmental Variables and Sinapis alba Phytotoxicity. Water, Air, \& Soil Pollution, v. 231, n. 4, p. 1-19, 2020.

CONAMA. Conselho Nacional do Meio Ambiente. Resolução nำ 430, de 13 de maio de 2011. Dispõe sobre as condições e padrões de lançamento de efluentes, complementa e altera a Resolução no 357, de 17 de março de 2005, do Conselho Nacional do Meio Ambiente - CONAMA. 2011.

DANIEL, T. R. Avaliação dos afluentes e efluentes em sistemas de biodigestores em escala real para a produção de biogás e biofertilizante a partir de dejetos da pecuária leiteira. 2015. 63f. Dissertação de Mestrado, Universidade Federal de Juiz de Fora (UFJF), Juiz de Fora, 2015.

D’ASCENZO, G.; DI CORCIA, A.; GENTILI, A. et al. Fate of natural estrogen conjugates in municipal sewage transport and treatment facilities. Science of the Total Environment, v. 302, n. 1-3, p. 199-209, 2003. DOI: https://doi.org/10.1016/S0048-9697(02)00342-X. 
EMBRAPA. Anuário Leite 2019: novos produtos e novas estratégias da cadeia do leite para ganhar competitividade e conquistar os clientes finais. São Paulo, Embrapa Gado de Leite, 2019.

FENT, K.; WESTON, A. A.; CAMINADA, D. Ecotoxicology of human pharmaceuticals. Aquatic toxicology, v. 76 , n. 2, p. 122-159, 2006. DOI: https://doi.org/10.1016/j.aquatox.2005.09.009.

FISCHER, N. Cloração de água com 17-beta-estradiol e utilização do teste YES para avaliação de estrogenicidade. 116 f. Dissertação (Mestrado em Ciências: Engenharia Hidráulica e Saneamento), Universidade de São Paulo - Escola de Engenharia de São Carlos, São Carlos, SP, 2013.

IBGE. Instituto Brasileiro de Geografia e Estatística. Produção da pecuária municipal. Rio de Janeiro, v. 44, p. 1-51, 2016. Disponível em:

<biblioteca.ibge.gov.br/visualizacao/periodicos/84/ppm _ 2016_v44_br.pdf>. Acesso em: agosto 2020.

INMET. Instituto Nacional de Meteorologia. Disponível em: <inmet.gov.br/portal/>. Acesso em: agosto 2020.

JORDÃO, E. P.; PESSÔA, C. A. Tratamento de esgotos domésticos. 7 ed. Rio de Janeiro: ABES, 2014.

KONZEN, E. A. Alternativas de manejo, tratamento e utilização de dejetos animais em sistemas integrados de produção. Sete Lagoas: Embrapa Milho e Sorgo, 2000.

LATHERS, C. M. New scientific role for clinical pharmacologists: Endocrine disruptors. Impact on human health, wildlife, and the environment. Faseb journal, v. 15, p. A1226-A1226, 2001. DOI: https://doi.org/10.1177/0091270002042001001.

MACIEL, A. M.; SILVA, J. B. G.; NASCIMENTO, A. de M.; PAULA, V. R. de; OTENIO, M. H. Aplicação de biofertilizante de bovinocultura leiteira em planossolo. Revista em Agronegócio e Meio Ambiente. Maringá, PR. v. 12, n. 1, p. 151-171, 2019. DOI: https://doi.org/10.17765/2176-9168.2019v12n1p151171.

MATOS, A. T. Curso sobre tratamento de resíduos agroindustriais. Departamento de Engenharia Agrícola e Ambiental/UFV. Fundação Estadual do Meio Ambiente. 2005.

DE MENDONÇA, H. V.; OMETTO, J. P. H.B.; OTENIO, M. H. Production of energy and biofertilizer from cattle wastewater in farms with intensive cattle breeding. Water, Air, \&SoilPollution, v. 228, n. 2, p. 72, 2017. DOI: https://doi.org/10.1007/s11270-017-3264-1.
MULLER, M. et al. Chemical and biological analysis of endocrine-disrupting hormones and estrogenic activity in an advanced sewage treatment plant. Environmental Toxicology and Chemistry: An International Journal, v. 27, n. 8, p. $1649-1658,2008$. DOI: https://doi.org/10.1897/07-519.

DE QUEIROZ, F. B. Desenvolvimento e validação de metodologia para determinação de fármacos e perturbadores endócrinos em amostras de esgoto utilizando extração em fase sólida e cromatografia líquida acoplada à espectrometria de massas. 2011 . 132f. Dissertação (Mestrado em Engenharia Ambiental), Instituto de Ciências Exatas e Biológicas, Universidade Federal de Ouro Preto, Ouro Preto, MG, 2011.

RESENDE, T. C.; NETO, J. M.; AZEVEDO, T. S.; BOTTREL, S. E. C.; PEREIRA, R. O. Estudo Comparativo Entre as Concentrações de Hormônios Reportados em Matrizes Ambientais Aquosas no Brasil e no Exterior. In: Congresso ABES - FENASAN 2017. São Paulo. 2017.

RICO, C.; GARCÍA, H.; RICO, J. L. Physical-anaerobicchemical process for treatment of dairy cattle manure. Bioresource Technology. v. 102, p. 2143-2150, 2011. DOI: https://doi.org/10.1016/j.biortech.2010.10.068.

ROUTLEDGE, E. J.; SUMPTER, J. P. Estrogenic activity of surfactants and some of their degradation products assessed using a recombinant yeast screen. Environmental Toxicology and Chemistry, v. 15, n. 3, p. 241-248, 1996. DOI: https://doi.org/10.1002/etc.5620150303.

SHORE, L. S.; GUREVITZ, M.; SHEMESH, M. Estrogen as an environmental pollutant. Bulletin of Environmental Contamination and Toxicology. v. 51, n. 3, p. 361-366, 1993. DOI: https://doi.org/10.1007/BF00201753.

SILVA, W. T. L. et al. Avaliação físico-química de efluente gerado em biodigestor anaeróbio para fins de avaliação de eficiência e aplicação como fertilizante agrícola. Quím. Nova. São Paulo, SP. v. 35, n. 1, p. 3540, 2012. DOI: https://doi.org/10.1590/S010040422012000100007.

US. EPA. 1997. Special Report on Environmental Endocrine Disruption: An Effects Assessment and Analysis, U.S. Environmental Protection Agency, Report No. EPA/630/R-96/012, Washington D. C.

VEGA-MORALES, T; SOSA-FERRERA, Z.; SANTANARODRÍGUEZ, J. J. Evaluation of the Presence of Endocrine-Disrupting Compounds in Dissolved and Solid Wastewater Treatment Plant Samples of Gran Canaria Island (Spain). BioMed Research International, v. 2013, Article ID 790570, 15p, 2013. DOI: https://doi.org/10.1155/2013/790570. 